\title{
The Art of Asking and Answering: Events, Things, and Librarianship in the Disciplines
}

\section{Michael Kicey}

University at Buffalo (SUNY)

\begin{abstract}
This essay, which is primarily addressed to academic liaison/subject librarians, considers the degree to which the economically-centered rhetoric of resource production, distribution, and consumption - a language that centers librarianship on the management of things - has pervaded the institutions and practices of modern academic subject librarianship. Drawing on sources in history, literature, and philosophy, the discussion then seeks to recover and restore our sense of library resources as acts of communication between human beings, and proposes an alternate language to help structure and direct the practice of librarianship at a crucial juncture in the history of higher education. This proposed language views librarianship in particular, and intellectual life in general, as a meaningful network of events. The argument concludes by proposing a number of core functions for liaison/subject librarians to develop as they adapt the proposed new viewpoint to the intellectual life of their respective institutions.
\end{abstract}

Keywords: open educational resources, cultural stewardship, norms and normativity, open access, philosophy of librarianship, interdisciplinarity, research, instruction, teaching, collaboration, scholarship, collections development, higher education, liaison librarians, subject librarians, academic librarianship

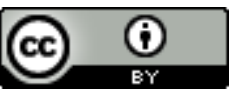

This is an Open Access article distributed under the terms of the Creative Commons Attribution 4.0 International License (http://creativecommons.org/licenses/by/4.0), which permits unrestricted use, distribution, and reproduction in any medium, provided the original work is properly cited. 
The foundation of one's thought is the thought of another; thought is like a brick cemented into a wall. It is a simulacrum of thought if, in his looking back on himself, the being who thinks sees a free brick and not the price this semblance of freedom costs him: he doesn't see the waste ground and the heaps of detritus to which a sensitive vanity consigns him with his brick.

The work of the mason, who assembles, is the work that matters. Thus the adjoining bricks, in a book, should not be less visible than the new brick, which is the book. What is offered the reader, in fact, cannot be an element, but must be the ensemble in which it is inserted: it is the whole human assemblage and edifice, which must be, not just a pile of scraps, but rather a selfconsciousness.

Bataille (1992, p. 9)

When we use the same words to describe the same phenomena for a long time, we are inclined to forget that there are different ways of approaching those same phenomena through words that give us a different grip on them, a different path of attack, a different set of possibilities. Sometimes nothing more than a bold metaphor, thoughtfully developed, can liberate us from ways of thinking that were constraining us and damping down our energies. Such concerted shifts in the language we use to describe our work and our aims are not merely cosmetic - when they are applied thoughtfully and consistently to our everyday environment, they can directly result in seismic shifts in practice and even in institutional culture. Talking in a different way can lead to thinking in a different way, and thinking in a different way can lead in turn to fertile and unforeseen revolutions in what we actually do, the institutions we uphold, and the services we provide.

Subject librarians talk a great deal, they talk to many different people in many different settings, and they recognize the value and the power of talk. The particular way of talking I want to discuss, furthermore, forms a crucial element in the professional and intellectual roles performed by subject librarians, who regularly negotiate between the full range of library collections and services, library personnel, student populations, teaching and research faculty, and administrators. Occupying 
this position, subject librarians are especially well situated to take a comprehensive view of the library within the university, to witness the far-reaching and multivalent effects of institutional practices and habits, and above all to appreciate the daily intimacy shared by the mundane and the exalted in the life of the mind. In short: we hear this language from many people, we see the effects it has on almost everyone, and we wonder whether it reflects the very best we can do.

The language I want to address makes an appearance whenever we speak of resource discovery and delivery, the marketing and promotion of collections and services, and especially the production, dissemination, and consumption of knowledge. We are so accustomed to hearing this kind of language in librarianship that we have ceased to hear it in a meaningful way, to hearken to its assumptions and its implications, and ceased to remark the profound paths it has struck into our habits and attitudes. Rather than simply and transparently reflecting a state of affairs that only allows itself to be described in one way, in this way, the language that speaks here is actually a distant outgrowth of what was originally a metaphor. That is to say: it is language originally meant to describe one object or domain of objects which has been applied wholesale to a different object or domain. Metaphors are justified by the degree to which they assimilate unfamiliar to familiar, or complex to simpler experiences; they are problematic, however, insofar as this assimilation is never perfect, and they become dangerous when they begin to conceal rather than reveal the phenomenon to which they have been transferred.

At its core, this metaphor assimilates libraries, their collections, their services, their staff, and their whole embeddedness in society, to the vast rationalized system of production and consumption that characterizes the political economy of the modern world. According to the logic that underwrites this metaphor, libraries, like productive and well-ordered factories, select, acquire, and stockpile resources, and process those resources into more useful and more accessible forms by a process of 
organization and (re)presentation. Secondly, they discern the full range of customer needs and reconcile these needs with the available supply of product. Finally, they distribute and disseminate these highly processed products to their customers - all while employing time, labor, and material according to optimal standards of efficiency. This metaphor of production and consumption continues in parallel on the 'customer' side. The students and researchers who use libraries perform a parallel process of production. They locate, evaluate, and analyze resources discovered in the library's stockpile. Next, they process, synthesize, and augment the contents of these resources by transforming them into new and more useful forms. Finally, they distribute and disseminate the products of their research to their own 'customers' - that is, other researchers who will take up these products in their turn and transform them again. As in modern political economy, consumption mirrors production, and in fact constitutes a productive process of its own. The aim of the integrated cycle is to maximize the wealth generated - in this case, the 'wealth' of knowledge - by the accretion of value, and to remove as many obstacles as possible from its free acceleration and expansion in all directions (Worthen, 2018). ${ }^{1}$

This total picture of the embeddedness of libraries in their socioeconomic environment forms the basic assumptions behind the metaphorical language of discovery, production, dissemination, and consumption that I have identified. It becomes comprehensible and usable to the professional who reads and hears it only when understood against this broader conceptual background - a background so basic to how professionals in general, not just librarians, orient themselves in the modern economy that it has fallen below the level of visibility or audibility for most of us.

\footnotetext{
${ }^{1}$ It is worth mentioning that the rhetoric of production and consumption underwrites much of the current push for outcome-based assessment models both in academic libraries and in higher education writ large - hardly surprising, since in many ways assessment measures and student evaluations are formulated on a transparent analogy with sales/marketing data and customer satisfaction surveys. This is not the place to take a position in the complex debate around assessment, but Molly Worthen's piece in the 23 February 2018 edition of the New York Times approximates my views well.
} 
But as I've already suggested, this extended metaphor for how libraries work and what they do has even less visible assumptions and implications built into it. The most important of these for the point I want to make here has to do with how this language conceives of knowledge or understanding, which forms the focal point and motivation for the entire process of production and consumption I have described. In a word, the economic metaphor construes human knowledge or understanding as a thing, a tangible product of labor, which can be created, maintained, reshaped, distributed, or destroyed - but above all, as a commodity that is a deposit of value, in the shape of time and labor, and is exchangeable against other such commodities.

Now, globalized corporations are de facto the masters of production and consumption in our time. I hardly need to point out that there has been a great deal of discourse - some of it sensible, some of it inflammatory, some of it collaborationist - about the corporatization of higher education, about the organization and administration of its institutions on models that mimic or even flatly reproduce corporate structures. It requires no great leap, therefore, to see that whenever we deploy a language of production and consumption to describe what academic libraries can and can't do, what they contribute to their institutions and their societies, and how they function within themselves and within larger wholes, we are throwing wide the gates of Troy to a great wooden horse. Insofar as we believe that the institutions for which we have the privilege of working should resist corporatization because, broadly speaking, we reckon that the educational process should aim at different, perhaps higher goals than the economy at large - then by using such language, we are inviting into not just our institutions and our working lives, but also into our hearts and minds a discourse and a set of practices which at best are not consonant with, and at worst actively undermine, some of our highest ideals.

I want to delimit this claim very carefully. I am not arguing that there is or was no justification for the use of an economically-derived language of commodified "things" in librarianship. Considered 
from the viewpoint of words pure and simple, "thing"-language has offered a well-fitting and richly justified conceptual armature that comprehends and structures the work of libraries well. In more practical terms, furthermore, it has proven enormously beneficial to the library profession and to academic communities in more ways than I can meaningfully enumerate here. In neither intellectual force nor pragmatic clout, then, has the logic of production and consumption as applied in academic libraries proven any exception to the wholesale transformation undergone by modern society chiefly by means of its thoroughgoing subjection to this model.

Still, this logic and its language have become habitual for us, and it lies in the nature of habit to render everything we experience inert and neutral, part of "the way things are" rather than "one way that things can be". When habit reaches this point, it tends to actively obstruct the emergence of other modes of speaking and acting. This habituation is particularly pernicious in a time when it is precisely economic forces in higher education that are working to exclude or exploit vulnerable populations and to scale the quality of education that students ultimately receive against the price they are willing to pay for it. In effect, this language not only blocks our ever-present capacity to find a new experience of the same work we have done for years or even decades. I believe it also hinders our efforts to educate our communities no less than our communities' efforts to be educated. We must ask ourselves difficult questions: are information, knowledge, or human understanding really things? Or is it simply expedient to think so, in certain contexts and with certain aims in mind, and inexpedient or dangerous otherwise? Is education itself a thing - a product or a commodity? Are universities producers, and are students consumers, of these products? Are library resources quantifiable in value in the same way as potatoes, crude oil, or silicon? Are libraries nothing more or less than resource distribution centers? Do we cringe a little to answer in the affirmative to any of these questions? 
So: is a new experience, a new approach to the library possible? And is there a new language, a new set of metaphors, a new rhetoric that is more adequate to this experience, and stands to transform our habits and attitudes on just as deep a level as the "thing"-language of the modern corporation has? I believe there is - and indeed, the constituents of this experience are at our fingertips every day without our realizing how they can be gathered and grasped into a meaningful whole.

On an ordinary day, when we stand among the stacks in a library and scan the shelves full of books old and new, or when we scroll through lists of results in an online catalog or database, the "thing"-language I have described represents a strong temptation to us in grasping our experience. The library and its varied contents strike us very strongly as things - a building or a database - that contain other things - print and digital books, journals, maps, images, video, raw data. It is precisely in approaching it as an assemblage of things that we can select, acquire, and ingest resources of value for our communities, and then, as they circulate among users, organize, control, and administer what might otherwise be limitless chaos and disorder. From a certain point of view, much of modern librarianship hinges on both what things need from people and what people need from things. Similarly, when researchers enter the physical library or access its digital counterpart, they are usually seeking very specific objects to put to very specific uses. And when the work they perform with our resources is completed and published - that is, when it has been transformed into yet another thing it takes its place alongside the thousands or millions of other things the library keeps on hand to spur on further research.

But what happens when, standing there among the stacks or gazing at a results list, we take down and open up a book from the shelf, or we open a full-text document, and allow the voice of the writer to find its way to us? Now, some astute readers may sense at this moment that, being a humanist, I'm about to launch into a panegyric about hearing the voice of Shakespeare, or Emerson, or 
Proust, in the silence of the library. For that reason, they may think that what I'm about to say will not mean much to a researcher in computer science rapidly scanning an article for a specific formula, or a biologist looking for a diagram of RNA production, or a physicist seeking a data set connected to the discovery of the Higgs Boson. This is not so. Insofar as, for the most part, contemporary academic libraries offer their users nothing more or less than symbols printed on a page or displayed on a screen, this moment of hearing the voice behind those symbols is still fundamental to the library experience. This is true no matter what discipline the user comes from, no matter what concerns and interests they bring, no matter how they find their way into that moment. When we take down that book, open that article, scan that data set, and the organized information they contain finds its way into our reading minds, we are compelled to recognize at certain moments that whatever things we happen to be dealing with - the books, articles, and data, the stacks, software, and server infrastructure - are nothing more than contrivances for capturing and perpetuating acts of communication: moments in which one person finds something to say to one or more other people, and says it. An act of communication is only very imperfectly described as a thing: we come closer to its essence if we call it an event.

From the broadest viewpoint, libraries are built for the sake of events, not for the sake of things. Because of libraries, the moment - be it ever so far from us in space or time - in which the writer attains her understanding and undertakes to communicate it becomes directly linked to the moment in which we hearken to that communication, come to participate in that act of understanding, and attain an understanding of our own. Let it be mediated by ever so many material interventions transcription, redaction, revision, translation, excerption - and let it be subject to ever so many misunderstandings - inattention, anachronism, cultural or linguistic difference - what happens in this contact between two moments is the perpetuation of a human act, from person to person, in the 
continuum of lived time. When I invoke Einstein's formula for the mathematical relation of mass to energy or when I recall a passage in the Autobiography of Malcolm X, when I write about Gödel's critique of Russell and Whitehead or when I translate Montaigne into Spanish, I am in all these cases receiving an act of communication and passing it on to others in a form more or less deeply marked by my own desires, my own mistakes, and my own understanding. In short, I am making myself into a medium through which the singular events of understanding embodied in these texts multiply, propagate, and keep happening. When libraries do what they are supposed to do, when the reader attains both her quotidian and her transcendent aims in our buildings and on our websites, we are in the business not of getting, keeping, and circulating things, but of perpetuating, accelerating, and amplifying events - events of understanding, of insight, of pulling it off and getting to the point. If we are still standing in the stacks at a moment like this, we attain a different vision and, I would argue, begin to speak a different language to describe our experience. The things on the shelves, in the database, on the repository site lose some of their tangible substance, but they gain extraordinarily in significance, when we see them now as simply way-stations, points of passage, or vectors of transmission through which countless millions of events, the sudden siblings of the moment of understanding we undergo in contact with them, are perpetuated, accelerated, and amplified in time.

By all means, however, let's keep a clear head about what is involved in changing our language from the viewpoint of things to the viewpoint of events. I have already admitted that the logic of things is an extraordinarily powerful one, and is chiefly responsible for the wholesale transformation of human life coincident with the rise and progress of the modern world. This is because things are eminently manageable: like books, they fit our hands and our minds. We grasp things, and through things we come to grips with the entire universe. Our grasp of events, on the other hand, is partial and transitory, when we grasp them at all. Despite all our efforts to render them manageable, events have a 
will of their own: they approach from unforeseen directions and release unintended consequences.

Nobody makes events: events happen. Events are by nature confusing, frightening, and frustrating: we justifiably prefer things, and are only too happy to render events tractable by transforming them into things. Yet it remains undeniable that if the most exceptional achievements in the arts and sciences share a common character, they do so precisely by virtue of an extraordinary and unprogrammed convergence of the unlikeliest forces and characters - that is, by virtue of being events - rather than by executing the kind of meticulous, step-by-step plan that reliably produces things. ${ }^{2}$ Similarly, when we critically examine the life of a single idea in time, we increasingly conclude that far from being things, ideas properly live in the form of a linked series of events in the shared life of human beings. The life of a rich and valuable idea turns out to be a wild and unforeseeable adventure of understandings, misunderstandings, appropriations, and modifications, in which the idea takes fire in unlikely situations and falls dormant in others that seem highly favorable to its growth.

The advantages of embracing an event-language to describe the work of academic libraries grow even clearer when each of us considers the course his or her own higher education has taken. The architecture of college and university curricula and the structuring of tuition payments regularly deceive us into thinking of higher education as a package of products, the value of which the student extracts and internalizes one after another - introduction, prerequisite, elective, seminar, capstone and then pays for, usually quite dearly. For a moment, however, compare the way institutions structure and deliver education to the way in which we know ourselves to have been materially and intellectually

\footnotetext{
${ }^{2}$ My conceptualization of things and events in the present discussion depends on the work of two thinkers. First, I draw on Georges Bataille's (1988) thought on expenditure, servility, and sovereignty as presented in The Accursed Share, especially the "Theoretical Introduction" to his project (vol. 1, p. 19-41), "The Historical Data: III" (vol. 1, 115-142), and "What I Understand by Sovereignty" (vol. 2, p. 197-257). Second, Hannah Arendt's (1989) differentiation of making and acting, as well as her exploration of the dangers of action, in The Human Condition, especially $\S 1$ "Vita activa and the Human Condition" (p. 7-12), §26 “The Frailty of Human Affairs" (p. 188-192), and $\S 31$ "The Traditional Substitution of Making for Acting" (p. 220-230)..
} 
transformed by the educational experience, and you will notice an enormous divide. Unless every course in her degree program is prescribed by a cut-and-dry skill set to be acquired upon graduation, the most valuable and authentically educating experiences of the typical undergraduate - which rapidly become the experiences from our college years that each of us remembers, retains, and reflects upon in later life - virtually never follow a rigorous, assembly-line rationale whereby the student matriculates as raw material and graduates as a finished product. Some of our coursework, while opaque and difficult at the time, helps us build skills we will end up using in unexpected and unforeseeable ways, and in domains far removed from their point of origin, much later in our lives. A very small portion of our coursework brings us in contact with a thinker, an idea, or a phenomenon that sets us immediately and ardently aflame, or with a given discipline or profession that builds and tests our mettle enough to carry us throughout our productive lives. And some of our coursework, though it be ever so necessary and required, though we may have been ever so eager to undertake it, will inevitably make no impression on us whatsoever, and whatever seeds it might have otherwise sown in us fall on stony soil.

Each of these experiences has a meaningful and purposeful place in the curriculum. The course of study each of us pursues is not a delivery system for a series of mechanically identical products, nor is it an assembly line that reliably hammers out educated people at the end. Rather, it is a thoughtful and deliberate effort to expose students to as wide a range of experiences as possible, all of which have proven potential to lead them into passionate, meaningful, and ultimately joyful lives. The real juice, the real sustenance that any student derives from their education and that ends up nourishing them through life is the shared product of both broad exposure and fortunate accident: we never cook it up solely by following a recipe to the letter. It takes, and it should take, years - that is, time: time full of opportune convergences and passionate encounters, in order for this experience to unfold. This is 
precisely because education, too, is not an ensemble of things, not a possession to be stored away or used up or replenished or bartered on or tossed aside. It is a happening, a story, a series of events, in which the brief spate of my living gradually finds its steady current within the turning flow of all time, in which my moments of understanding find themselves bound by unseen threads to the golden braid of human life entire ${ }^{3}$.

When subject librarians confront the phenomenon of time, it usually assumes a purely negative form. In the form of wear and tear, time depreciates and destroys collections; in the form of technological progress, it disrupts the practical basis for library services; in the form of habit and inertia, it introduces friction into institutional structures or bogs people down in boredom, passivity, and cynicism; in the form of generational divides, it creates points of disconnect and misunderstanding between populations. On the other hand, when called upon to express the most vital and the most exciting contemporary developments in public services at academic libraries, subject librarians will frequently, reflexively, and enthusiastically invoke concepts related to space. We talk constantly about

\footnotetext{
${ }^{3}$ Many forces other than the strictly economic have contributed to the transformation of human communication into a thing of the sort I describe here, but two particularly powerful such forces can be found in the invention of writing and the subsequent development of printing technology. Over many centuries, these technologies have eroded our awareness of communication as a fragile process tightly bound to speaker and situation, that is, to time, and replaced it with the idea that we communicate through the exchange of (apparently) stable, permanent, and self-sufficient objects in space. Written or printed words, radically liberated from a transient situation and freely disseminating among an absent and indeterminate posterity, have everywhere contributed to this rigorous spatialization and objectification. Walter Ong's seminal work Orality and Literacy (2002) is the classic treatment of these issues in history, technology, and culture, especially Ch. 5, "Print, space and closure" (p. 115-135). Ong presciently argues at various points that the rise of digital communications technology has initiated yet another reconceptualization of the communicative process, and the concepts applied by the present argument try in part to witness and describe this transformation beyond Ong's early statement. In the transformation now underway, we see certain characteristics of the culture of writing/print either receding - such as the stress on the permanence and self-sufficiency, the thingness of texts - or intensifying - for instance, the distanciation or 'absencing' of the writer from the written, or the power of written texts to disseminate and circulate indefinitely. At the same time, certain characteristics of oral culture - such as the understanding of communication as an ephemeral, time-bound event, often without lasting trace - have witnessed a resurgence. All of which is to say: while the basis of the present argument is often conceptual, it has a significant foundation in historical and empirical realities with which librarians daily reckon.
} 
creating new kinds of library spaces that house and deliver new kinds of resources, reconfiguring existing spaces to facilitate the pursuits of patron groups with different needs, and shifting patron concepts of the library away from the spatial categories of "warehouse," "storage facility," "reading room," and toward other, equally spatial categories: "laboratory," "workshop," or a catchall "place for collaboration." Much of the excitement around these transformations is justified: it is right and good for librarians in this moment to pursue critical thought and practical activity around not merely what these spatial containers contain, but how they structure and perhaps even produce what they contain. But we can take this transformative drive a step further and grasp its meaning at the root. If I am right to argue that education is event and not product, that the life of the mind is a life lived in and with time and its events, then subject librarians should by rights see themselves not only as stewards of resources stored up in buildings or on servers, nor only as designers of stimulating and responsive spaces for interaction between human beings and information. They must also, and primarily, view themselves and their institutions as the coefficients and midwives of time, in the salient form of events.

Even the sympathetic reader may, at this point, feel quite at sea in trying to approach the concept of time as a meaningful basis for the administration of library services and collections. Time as such seems flat, gray, empty, diffuse, and above all, abstract: beyond the contours given to time by our mechanical measurements - seconds, hours, weeks, decades - or by our rationalized, industrialized exploitation - datebooks and planners, punch clocks and wages, funding cycles and annual reviews time opens out upon the trackless expanse of pure duration, without boundary or limit. The events that do, after all, fill and shape time are by definition so fleeting, indefinite, and impermanent that we habitually render them concrete and manageable, as I have already argued, by transforming them into things. Space, moreover, can easily be hammered into a number of familiar, durable forms that distinguish, classify, organize, store, and deliver these things. The arts and sciences of architecture, 
interior design, and urban or campus planning, as well as the younger practices of information architecture and web design, yield a wealth of spatial-visual techniques for producing coherent, permanent, and legible spaces and for disposing all our human things within them - so that we can get at them, and get at each other in them. Human spaces are architectural, in either the literal or the figurative sense of the word: they are conceived, constructed, and utilized in comprehensible shapes that we choose according to present and future purposes. But what is the architecture of time? Does it even have one?

This is not the place to propose an architecture of time as such - I will gladly leave that to the philosophers. We can, however, propose a model for the kind of time that is most pertinent to the work of libraries and librarians, and above all to the work of those who use them: artists, critics, historians, theorists, scientists, engineers, clinicians. The architecture of time that reveals itself in intellectual life, in the ferment of events that animates the classroom, the seminar room, the laboratory, the studio, the examining room, and yes, the library, and without which these spaces and their contents are mute and inert indeed, is the contour and rhythm of conversation. Nature and humanity together, the physical and the social worlds, pose to human beings the fundamental and persistent questions linked to our finite being; colleges and universities, in the shape of the extraordinary and daily-renewed effort of their millions of students and researchers and staff, strive to answer them. This fundamental two-part rhythm, questions and answers, the respiration of the spirit - is it not just as infinitely flexible, capacious, and fluent an architecture for the behavior of thought in time as the vast edifices of our cities, factories, and ports are for the behavior of matter in space? ${ }^{4}$

\footnotetext{
${ }^{4}$ Most recently, conversation also has had the great good fortune of becoming precisely the controlling metaphor of scholarship in toto according to the ACRL Framework for Information Literacy for Higher Education (2016), and thus the primary model by which librarians and other instructors in American higher education seek to communicate the most accurate and comprehensive image of intellectual life to rising generations of students. If
} 
Like many of my colleagues, in every library instruction session I offer, I introduce the session with precisely this idea, and at every subsequent point in the presentation strive to link the specific skill or tool under discussion back to the idea of scholarship as a conversation. In discussing the cycle of scholarly publishing and even the nuts and bolts of database searching, I emphasize not merely the utility, but the creativity and fertility of libraries as institutions devoted to the perpetuation and propagation not merely of paper, ink, or megabytes, but of human interactions and shared realizations. I try to show them, in a word, that libraries are a mundane miracle: a vast and genuinely awe-inspiring technology whereby we may listen word-for-word to the thoughts of the long dead and teach all we know - and much more than we know - to generations who will not ask their first questions for another millennium. Libraries ensure no lively conversation need ever fully fade or die, but can be picked up and carried forward again by a new partner centuries hence. And it happens because librarians find ways to continue, amplify, and intensify the rhythm of questions and answers.

So: the life of the mind, of research and teaching, consists of an ongoing conversation rooted in the human capacity to ask concerned and meaningful questions and to offer rational, provisional answers to them. The integrity and the pertinence of scholarship and teaching depend on an interaction between questions and answers that is free and open, but also rigorous and sound. Originally dispersed in both time and space, but unified by its own inner coherence and strengthened by the persistence of its material basis, conversation continues and elaborates a complex confluence of just such events of understanding, each of which has left its rich sediment in the riverbed of inquiry and lent its momentum to the total force of the stream. Above all, the responsibility of inquiry, the

conversation offers the preeminent metaphor, the best "teachable concept" of what scholars do, and if this is the model we seek to communicate to students in part to help them make sense of a bewildering information environment, are we as librarians not also beholden to the same model to understand what we do, and then also to do it well? 
ethos of conversation, demands that scholars and librarians alike treat intellectual life only secondarily as a making, and primarily as a doing - only secondarily as a thing in space, and primarily as an event in time. Librarians in general, and subject librarians in particular, play the central practical role in negotiating this interaction and are complicit in its operation from beginning to end. They help these conversational events of understanding happen in the first place, and then they help them ramify and persist beyond the moment of their happening, to reach unforeseeable, perhaps even unthinkable, ultimate destinations. Colleges and universities and the libraries that support their activities exist in order to bear forth this event, the event of understanding, as frequently as possible, even continuously, because understanding is an event that keeps happening, that in fact wants to keep happening, and because this happening preserves, enriches, and exalts our human being.

As librarians, we tend to view ourselves, often with good justification, mainly as stewards of things - managers of collections, databases, websites, funds, labor, library buildings, relationships - or as sophisticated mediators between human beings and the things they need - research consultants, reference experts, skill-set instructors. All I have argued thus far, on the other hand, suggests that subject librarians must recognize that the things they offer only become meaningful and purposeful from the events, interactions, and conversations for which these things provide the admittedly necessary foundation, instrumentation, or occasion. In a word, we should begin to view ourselves as the facilitators and perpetuators of events. expert, sophisticated, and irreplaceably crucial agents on behalf of understanding in time.

This conception of the work of subject librarians in particular issues in five core functions, with which I will conclude this discussion. The content of these functions may sound familiar in part, but their interlocking structure, informed by the new metaphors l've tried to develop here, orients our work in a new direction, gives it a clearer purpose which also happens to be more in line with our shared 
ideals, and resists the relentless levelling-down 'thingification' of higher education and intellectual life more broadly.

1. The open hand: creating and maintaining access. Ever since ancient librarians started keeping their scrolls under lock and key, librarians have actively exercised control over access to libraries and their collections and have thought critically about what kind, degree, and manner of access is best. It is vital for us, in our historical moment, to perceive that the best paradigm for understanding resource access in the contemporary academic information environment is neither the opening of a book nor the illumination of a screen. Rather, the paradigm can be found in the gesture of welcome, the convivial introduction, and the brief but illuminating orientation by means of which we integrate an interested stranger into a conversation between experts already in progress. In facilitating this primary event of encounter, librarians become agents of what might be called the hospitality of understanding, the humane process by which strangers, exiles, and outsiders are made first into guests of the house, and then into its hosts, and by which they gradually convert from the silence of incomprehension to the fluency of involvement. Fulfilling the demands of this hospitality, furthermore, enacts at one and the same time the intellectual, the ethical, and the political functions of librarianship: it enriches the discussion, it humanizes the newcomer, and it democratizes the movement of thought. Decisions about access can no longer afford to polarize the field between users and resources, between people and information, all of which is just one more way to divvy up things, to control, domesticate, and rigidify them, to neutralize their potentials and limit their relations. Rather, we should view users, resources, research projects, and institutions as shifting nodes within a rich and ever-growing network of events, of questions and answers, of moments and experiences. In practical terms, this means firstly that full-throated (and full-pocketed) support for the ensemble of methods, approaches, and practices of the open access (OA) and open educational resources (OERs) movement 
should be at or near the top of the institutional agenda for subject librarians and academic library administrators. Secondly, it means that collections policies should be built on the principle of optimizing the flow and flexibility of information resources in scholarly and teaching activity, rather than maximizing the sheer quantity or breadth of information resources possessed. Rather than print weeding projects, for instance, presenting an onerous collective task undertaken once every five or ten or twenty years, deaccessioning should become as regular a part of the week-to-week work of libraries as acquisitions. Robust, nuanced, contextually-appropriate weeding policies should accompany collections development policies to ensure consistent and continuous workflows and, above all, to help maintain a flexible, coherent, responsive collection. Thirdly, it means that librarians act in every moment as highly approachable and permeable gateways into scholarly engagement for underrepresented or underequipped newcomers, regardless of institutional, departmental, or cultural barriers.

2. The pointing finger: teaching standards and values. The relatively unforeseeable free flow of exchange in intellectual life does not mean that these events should occur entirely at random, without definite boundaries or structures imposed on them by their human participants. In fact, the specific kind of conversations cultivated in the arts, humanities, and sciences derive their value and potency from the standards they adopt, the protocols they follow, and the obligations they are bound to meet. These constraints, furthermore, are not merely empty etiquettes, but instead constitute the common accountability of researchers to the discipline imposed upon them by the search for truth. For scientists, this accountability includes the verifiability of results and the reproducibility of data by other researchers, the logical criteria of empirical reasoning, or the adherence to ethical and humane standards in experiments involving animate beings. For humanists, it includes the accurate and representative use of documentary evidence, the argumentative standards of inductive and deductive 
logic, or the acknowledgment of sources. Now more than ever, manifold forces - technological, professional, and political - threaten these respected and amply justified controls on scholarly conversation. These forces undermine the integrity of the consensus that humanists and scientists strive to maintain and also place pressure on students in particular, but on rising scholars as well, to use or produce information without awareness of, or respect for, the criteria that scholars use in order to validate their own findings or accept those of another. As facilitators and instigators of scholarly conversation, it falls to librarians to teach newcomers not simply what the norms and values of intellectual life are, but the reasons why they are norms and values, their practical, moral, and intellectual basis, and the risks associated with departing from or subverting them. In the present environment, it cannot be said often enough that scholars do not adhere to these norms and uphold these values because they are the empty trappings of academic elitism or the hidebound vestiges of forms of authority long since rendered obsolete by our brave new - and increasingly anarchic - world. Rather, they adhere to these norms and values because without them, quite literally, the lights go out, the planes fall from the sky, our water turns undrinkable, our roads fall apart, and our words cease to have any meaning except as substitutes for blows. Librarians must make the case that our conduct in conversation - whether in scholarly debates or in quotidian exchanges - does not silently recede into the glittering empty morass of online sound and fury, as simply more noise drowning in an ocean of noise. We must demonstrate instead, and tirelessly, that words and deeds are irrevocable events, which endure, and are meaningful, and bear real consequences - intellectual, moral, and practical - for all who engage and interact. We perceive the urgent need to make this case as soon as we perceive that quality of our resources and data of which I wrote earlier: their essential nature as acts of communication, from one human person to another human person, rather than as mere 'thingified' commodities transacted indifferently between us. We may regret or take back something we have said 
or done, but we cannot unsay or undo it, and we cannot deny responsibility for it. In practical terms, this means that we reshape our teaching agendas to offer explicit and positive focus on issues of normativity in the disciplines we serve, take time to explain to newcomers how norms are created, maintained, and justified by consensus and peer review, and advocate on behalf of norms and against intellectual anarchy.

3. The seeing eye: discerning needs and motives. The art of conversation demands as much attention to what is unsaid, the questions that are not asked and the answers that are not given, as to what is actually said, asked, and answered. Every conversation takes a single itinerary through the infinite space of communication and opts out of all others, arrives at one final destination to the exclusion of every other. As professionals who work for years or even decades in the trenches of the scholarly disciplines, subject librarians are unusually well-situated to observe shifts, revolutions, and consolidations in the discourse as well as new ambitions, interests, or anxieties in those who contribute to it. The student or researcher who ventures a new path, who seeks a different destination, who speaks questions and offers answers heretofore unimaginable, can only stand to benefit from a guide and advocate who knows the breadth of the terrain, the narrowness of the paths that crisscross it, and above all the needs and motives of the one who wants to make the attempt. An important part of the task of subject librarianship thus consists in attending not merely to the shape of the conversation that is actually underway, to the direction of the events that are actually happening, but also and in equal measure to the plethora of merely possible exchanges and happenings that stand behind them, waiting their turn to be realized, as well as the interlocutors who are situated to bring them forward. Thinking in terms of events, unlike thinking in terms of things, demands a high level of sensitivity to such possibilities, the conditions in which they become viable and desirable, the resources needed to bring them to fruition, and the way their realization gives rise to new possibilities 
in turn. The realized event bears within it the seed of myriad possible future events, while the acquired thing can only persist and repeat itself indefinitely. In practical terms, this means that in addition to serving as highly approachable and permeable gateways to intellectual engagement for newcomers (see \#1 above), subject librarians regularly press the traditional agenda of the reference interview - to uncover what a patron really needs - beyond the institutional compartments, disciplinary divisions, or intellectual boundaries inside or outside the patron that dampen or stifle the possibilities of free interplay.

4. The open door: connecting and cross-pollinating. The consolidation of multiple liaison roles into fewer individuals, dictated by the budgetary and staff constraints many institutions currently face, has at least this felicitous outcome: that individual librarians develop multiple disciplinary literacies and thereby become nodes of extraordinary connection and exchange in ways both the librarians themselves and the scholars they serve do not anticipate. Such extraordinary exchanges become possible only on condition that the librarians see themselves not as merely facilitating contact between "users" and "resources" - people and things, once again - but as equal and committed interlocutors in interactions, in events that are mediated on multiple levels. While things tend to stay in place and remain self-identical unless they are moved or acted upon by human beings, thereby reinforcing existing structures and dispositions, events tend to ramify and proliferate across boundaries and barriers, above and beyond any human agency, suggesting new tendencies and territories. Librarians must see their working role as a medium of transmission, intersection, and refraction for these events just as water is for physical waves or a lens is for light waves. This requires a certain amount of subject expertise, but above all it requires - and exploits - the oblique status and extradisciplinary position of the librarian, who has the luxury of observing, for instance, debates about method or paradigm from multiple points of view, either inside or outside the discipline in question, in 
ways that intradisciplinary researchers often do not. In practical terms, this means that in a given discipline, the subject librarian should constantly act as a well-informed and broad-minded ambassador from the other disciplines she knows and represents. Rather than bemoan the marginal status of librarians in relation to the center stage of academic life, the subject librarian should likewise capitalize upon the outsider's viewpoint granted to them by their role and vocally articulate it to insiders.

5. The well-kept garden: stewarding resources. In emphasizing the role of events over the role of things here, by no means am I trying to suggest that there are not a great many valuable things rightly entrusted to librarians and libraries, without the care of which they would certainly perish: everything from the delicate and irreplaceable manuscripts of Herculaneum to the latest round of federally-funded GIS data. But our passionate regard and zeal for things should not persuade us that these things are valuable in and of themselves, as mere things. Their entire value lies either in the remembrance we have of the human events to which they have given rise in the past - the revolutionary idea, the epochal break, the foundation of a new order of society - or in our anticipation of equal or greater such events issuing from them in the future. Books, for one, are nothing more or less than staging-points for contact between the event of writing and the event of reading, as I argued earlier; the same goes mutatis mutandis for nearly every other form of information at our disposal. Like the neural networks within the human brain, the library constitutes an enormously complex matrix of potential circuits for energy, resources, and information. Just as neural pathways spontaneously break down and reorganize when they are not habitually reinforced by electrochemical activity, however, so the library must constantly and conscientiously reevaluate how energy, resources, and information are moving through and within it, and how its intricate structure of things can better respond to the forces and flows of events. In practical terms, I will reiterate what I wrote just now about the importance of 
maximizing the flow and flexibility of resources rather than their quantity and breadth. I add only that the subject librarian must make it a concerted and meaningful project in her work to reorient her viewpoint economically, institutionally, and intellectually from being structured by things, resources, or holdings to being structured by events, encounters, exchanges, or processes. As librarians, we must of course steward many things: books, databases, websites, buildings, servers, furniture, money - but if we know what we are about, and what the things we care for are really about, we must recognize that our care and concern in the last analysis belong to the free and living flow of the human mind, which surely grows sluggish and dull when it is not fed by the forceful currents that come to it from the arts, sciences, and humanities, but remains a greater and stronger torrent than any of these individually or all of them together.

\section{References}

Arendt, H. (1989). The human condition. Chicago: University of Chicago Press.

Association of College \& Research Libraries Board (2016). Framework for information literacy for higher education. Retrieved August 2018 from:

\section{http://www.ala.org/acrl/sites/ala.org.acrl/files/content/issues/infolit/Framework ILHE.pdf.}

Bataille, G. (1988). The accursed share: An essay on general economy (2 vols.) Translated by Robert Hurley. Zone Books.

Bataille, G. (1992). Theory of religion. Translated by Robert Hurley. Zone Books, 1992.

Ong, W. (2002). Orality and literacy: The technologizing of the word. Routledge.

Worthen, M. (2018, 23 February). The misguided drive to measure 'learning outcomes.' The New York Times. Retrieved August 21, 2018 from: https://nyti.ms/2sRSoam. 


\section{Acknowledgments}

I would like to acknowledge the help and support of Jessica Clemons, Dean Hammer, Chris Hollister, Dave Lankes, Howard Pikoff, and Laura Taddeo in the writing and revision of this piece. 